\title{
The Effect of Chromium and Herbicide on the Growth of Aspergillus terreus Isolated from Soil Environment
}

\author{
K. Saraswathi $(\mathbb{D})$, K. Vadamalaikrishnan (D) and P. Jayaraman (iD)* \\ Department of Botany, Government Arts College for Men (Autonomous), Nandanam, Chennai - 600035 , \\ Tamil Nadu, India.
}

\begin{abstract}
The release of various chemical substances by human activities in soil leads to change its soil properties and affect the life of microbes, plants and animals including human. Microorganisms, especially fungi play an important role in soil fertility and various biochemical features, which is affected by the contamination of heavy metals and Organo-chlorine compounds including herbicides. Therefore, the present study was focused on the bio-diversity of fungi from soil samples collected from leather industry (6 samples) and paddy field ( 6 samples) environment. Further, the frequently occurring species named Aspergillus terreus from the above soil was studied in vitro for the growth tolerance of chromium and herbicide (Pretilachlor) at various concentrations amended in PDA medium. The results indicated that the fungi such as $A$. niger, A. glaucus, A. terreus, A. nidulans, A. flavus, curvularia sp, Penicillium sp and sterile mycelia fungi were mainly present in the above soil samples. For quantitative pattern, leather industry soil showed 4,100 cfu/g to $30,600 \mathrm{cfu} / \mathrm{g}$ with an average of $16,896 \mathrm{cfu} / \mathrm{g}$ whereas the paddy field soil had $14,700 \mathrm{cfu} / \mathrm{g}$ to $33,720 \mathrm{cfu} / \mathrm{g}$ with an average of $22,215 \mathrm{cfu} / \mathrm{g}$. However, $A$. terreus and $A$. niger were present remarkably in the above soil samples. Hence, for the study of in vitro tolerance of chromium by $A$. terreus, the increased concentrations such as $100 \mathrm{ppm}$ to $500 \mathrm{ppm}$, the growth observed as in the decreasing level, whereas above $500 \mathrm{ppm}$, growth is completely suppressed. But, for the herbicide amendment in Potato dextrose broth, the fungi able to grow up to $1000 \mathrm{ppm}$ with decreasing level. The present study concludes that the species $A$. terreus could be an effective microorganism to degrade herbicide (pretilachlor) and moderately for chromium in the soil environment.
\end{abstract}

Keywords: Soil fungi, Paddy field, Leather Industry, Aspergillus terreus, Herbicide, Chromium, PDA

\begin{abstract}
*Correspondence: jayaramannp@gmail.com
(Received: March 28, 2020; accepted: June 30, 2020)

Citation: Saraswathi K, Vadamalaikrishnan K, Jayaraman P. The Effect of Chromium and Herbicide on the Growth of Aspergillus terreus Isolated from Soil Environment. J Pure App/ Microbiol. 2020;14(3):2093-2104. doi: 10.22207/JPAM.14.3.50

(C) The Author(s) 2020. Open Access. This article is distributed under the terms of the Creative Commons Attribution 4.0 International License which permits unrestricted use, sharing, distribution, and reproduction in any medium, provided you give appropriate credit to the original author(s) and the source, provide a link to the Creative Commons license, and indicate if changes were made.
\end{abstract}




\section{INTRODUCTION}

Soil is the major component of earth's ecosystem which contains organic matter, minerals, gases and large numbers of macro and microorganisms. The diversity of microorganisms such as bacteria and fungi is essential when monitoring environmental influences on soil quality and its atmosphere is supported by several interactions among its physical, chemical and biological components (Chandrashekar et al., 2014). There are many reports on biodiversity and influence of different species of fungi on various soil locations were available at global level which indicates the soil fungi are ubiquitous and inhabit different types of soils including polluted soil environment (Frac et al., 2015, Hannula et al., 2017; Frac et al., 2018 Jayaraman et at., 2018; Rosas-Medina et al., 2010). There are many factors causing land pollution and the most common among them are the release of effluents from various type of industries and usage of chemical in the agricultural practices. The discharge of industrial effluents especially without treatment may have profound influence on physio-chemical and biological properties of soil related to soil fertility (Akpomie et al., 2016). The effluent from leather processing Industries is a major cause that produces huge volume of wastewater contain poisonous heavy metals especially chromium that normally discharged to irrigated agricultural lands. This tannery wastewater contains some proteins from animal skins that are released during enzymatic processing of leather but also contaminants such as salts and chromium $(\mathrm{Cr})$, that might affect soil processes and crop production. According to various reports, the leather industry globally generates up to 5.4 million tons of solid and liquid waste each year which is one of the major pollution in soil environment. Noorjahan (2014) has studied the physicochemical characteristic identification of fungi and Biodegradation of Industrial effluent. According to Rasool and Irum, (2014) studied the isolaltion microorganism from industrial polluted soil reference to tannery effluent and reported that the filamentous fungi including varius species of Aspergillus and Pencillium grown and found resist to the tannery effluent.

The use of agricultural chemicals such as chemical fertilizer, pesticide and herbicide becomes an important issue in agricultural soil environment. The intensive use of pesticides causes concern both to public and scientists all over the world. Herbicides also used nowadays worldwide and the residues found variable toxicity. These herbicides could then accumulate to toxic levels in the soil and become harmful to microorganisms, plant, wild life and proved remain the most effective, efficient and economical way to control weeds. For this reason, several biological techniques involving biodegradation of organic compounds by microorganisms have been developed. The use of microorganisms such as different species of bacteria and fungi either naturally occurring or introduced, to degrade pollutants is called bioremediation. Therefore, certain fungi represent a powerful prospective tool in soil bioremediation and some species have already been patented. In vitro studies of degradation of the pesticide Chlorpyrifos conducted by Jayaraman et al., (2012) reported Trichoderma virede was more effective followed by $T$. harzianum and consortium of both the organisms. In contrast to the fungal suppression, Sclerotium, Trichoderma, Rhizoctonia, Penicillium and Aspergillus sp. showed enhancement at higher concentration of herbicide as well as other chemicals . According to Chukwuma (2015), the microbial biomass of an agricultural soil plays an essential role in degradation and mineralization of nutrient element and supply to plants through recycling. Whereas, certain herbicide exhibited the inhibitory effect on the mycelia growth of fungi. (Paula et al., 2007), studied the degradation of herbicide by fungi was increased from $14.42 \%$ to $35.01 \%$ after 10 days period. Two isolates of Aspergillus fumigatus and A. niger (87, $79 \%$ ) were found to be highly degrading the herbicide (butachlor) and form high level of biomass respectively (Sangeetha et al., 2018). Treatment of soil with glyphosphate degrading fungus would be useful in some areas where this herbicide is extensively used (Arfarita et al., 2014). Paraquat, Glyphosate and Atrazine showed higher inhibition potency on certain fungal mycelial growth than Primextra and Linuron (Chukwuma., 2015). Bacterial degradation of $s$-triazines and parachlorobenzene (PCB) is described and novel strategies to improve bioremediation are discussed (Michael et al., 2010). bioremediation 
of pesticides by the isolate microorganisms from soil could be used for remediation of pesticides contaminated soil and water (Nilesh et al., 2016).

Based on the above scientific background and the significance of chemical pollution such as chromium and herbicide released in the soil environment, the present study is focused with the aim of analyzing the soil samples for the occurrence of fungal species in the industry environment and paddy field environment soil. Further, the frequently dominating species of fungi such as Aspergillus species to be studied for in vitro growth tolerance against the chromium and herbicide (pretilachlor) amended nutrient medium. The results of the study will provide an idea of fungal tolerance of the above environment and lead to biodegradation aspects.

\section{MATERIALS AND METHODS Collection of soil samples}

The soil samples (12 Nos.) were collected from Leather industry environment located in Vellore district and the paddy filed environment located in Thiruvallur and Kancheepuram districts of Tamil Nadu during January to March 2019. The soil samples about $200 \mathrm{~g}$ were randomly collected by digging the soil about 5 inch depth by using cleaned spatula and metal spoons and packed in pre-cleaned polythene bags (LDPE bags) and tightly tied with rubber bands. Different soil samples collected in polythene bags were labeled properly with sample details such as source and date of collection and brought to the laboratory immediately in the laboratory for further analysis within a week time.

\section{Determination of moisture content}

The moisture content of the soil samples were determined by standard oven-drying method (Mishra, 1968). Exactly $5 \mathrm{~g}$ of freshly collected soil sample was weighed in a pre-weighed empty glass Petri-dish and the initial weight was noted. The petri-dish with soil sample was placed in a hot air oven for 2 hours at $105^{\circ} \mathrm{C}$. After drying, the soil sample of the petri-dish was cooled to room temperature and weighed for loss of weight i.e final weight. The weight of the Petri-dish with soil sample and the percentage of moisture content was determined. The following standard formula was used for the calculation of moisture content percentage.

$$
\% \text { of soil moisture }=\frac{\begin{array}{c}
\text { Initial weight (Petridish } \\
\text { with soil) }- \\
\text { Final weight }
\end{array}}{\begin{array}{c}
\text { Weight of soil sample } \\
\text { taken (5) }
\end{array}} \times 100
$$

\section{Analysis of fungi from the soil samples}

Different soil samples collected in the present study were analysed for the presence of fungi by serial dilution plating method using Pototo Dextrose Agar (PDA) is a nutrient medium (Walksmann,1950; Warcup,1950). Sodium chloride solution $(0.9 \% \mathrm{w} / \mathrm{v})$ was used as a saline for preparation of soil dilution. For the serial dilution method, $1 \mathrm{gm}$ of the soil sample was dispersed thoroughly in $10 \mathrm{ml}$ of sterile saline. From this sample solution, $1 \mathrm{ml}$ was transferred to $9 \mathrm{ml}$ sterile saline solution by using micropipette. The resulting solution was mixed well and from this $1 \mathrm{ml}$ was pipetted out into a test tube containing $9 \mathrm{ml}$ sterile saline. Likewise the sample dilutions were made up to the $10^{-5}$ and the dilutions of $10^{-2}, 10^{-3}$ and $10^{-4}$ were used for plating on PDA medium. About $1 \mathrm{ml}$ of soil suspension of each concentration was added and spreaded on sterile petri-dish containing antibiotic amended PDA medium by spread plate method. Replicates were maintained for each dilution of the samples. The inoculated PDA agar plates were incubated at $30+/-1^{\circ} \mathrm{C}$ in an Incubator for 3 to 7 days till the growth and sporulation of individual species of fungi were occurred. Then the culture plates were taken for observation of both qualitative and quantitative pattern of fungi. The observation was done and the data was recorded for interpretation of the results.

Qualitative and Quantitative study of fungi from soil samples

The occurrence of individual species of fungi present in various soil samples were observed and identified for the qualitative pattern. The colonies present in the sample inoculated culture plates were isolated by pure culture method and observed for the colony morphology and microscopical characters. The characteristic features such as colony colour, morphology, growth and appearance of the colony in PDA and CDA medium; microscopic characters include hyphae structure, conidiophore structure, structure and shape of conidiosporangium, number of sterigmata, conidia shape and structure 
of the individual fungal species were recorded for further identification. Then the individual species of fungi were identified by using standard identification manuals for Aspergillus, Pencillium and Hyphomycetes fungi (Raper and Fennel, 1965; Raper, Fennel and Thom, 1949; Barnett \& Hunter, 1971; Ellis, 1971).

The characteristic features of individual species of fungi are given below:

\section{Aspergillus niger}

Initially white and the colony appear with black heads after $3^{\text {rd }}$ day, rapid in growth, cottony in texture, reverse off-white to light yellow in colour, mycelium septate, conidiophore arise from fertile branch and with terminal globose shaped sporangium, sporangium bearing with phialides or sterigmata in biseriate and release globoid conidiospores, rich in spore production.

\section{A. flavus}

Colony white mycelium initially and with sparse green to normal green coloured heads with conidophores, rapid growth, radial pattern, cottony texture, reverse off white to light yellow colour, exudate produced in some conditions, septate hyphae, globose sporangium, sterigmata biseriate, round shapeds condiospores.

\section{A. glaucus}

Fast growing spreading rapidly, colony gray green to yellow colour after sporulation, reverse yellow to orange colour, exudate appear sometimes, spread fast on the surface of the culture medium, globose heads or sporangium, sterigmata uniseriate, globose conidiospores.

\section{A. nidulans}

White mycelium with dark green coloured conidiophores, restricted growth or slow growing, often white batches of mycelium appear in morphology, exudate appeared, smaller heads, globose to subglobose heads, biseriate sterigmata, globose to elliptical spores appear.

\section{A. terreus}

Colony appear initially in white mycelium and light brown to chocolate brown, velvette appearance, restricted growth to rapid growth, centre of the colony with dense condiophores with mycelium in the margin, conidiophores small, sporangium clavate to subclavaate shaped, sterigmata biseriate, dense and appear as flame from the vesicle, conidia small in size, ovate to globose.

\section{Penicillium sp.}

Colony in grey green to bluish green with white mycelium in the margin, yellow to off white in colour, mycelium dense and septate, short branches of condiophore, small sporangial heads, Pialide long with 2 to 3 seriate, conidia elliptical to subglobose.

\section{Pyricularia sp.}

Colony grey to black colour, loosly grown mycelium, reverse of the colony appear in black, septate hyphae, Conidia are solitary, pyriform to obclavate, narrowed toward tip, rounded at the base, 2-septate, hyaline to pale brown, with a distinct basal hilum, sometimes with marginal frill.

\section{Trichoderma viride}

The colony appears to be a bit granular on PDA, with green conidia distributed throughout with white mycelium. An irregular yellow zone without conidia was present around the inoculum. Some white pustules were also found growing on the geen mat of conidia, The conidia of $T$. viride were appear in clusters, globose, light green in colour, phialides were arranged in divergent groups of 2-4,

\section{White non-sporulating fungus}

White bushy mycelial colony, sometime dense and spread throught the culture medium, septate to non septate mycelium without any fertile branches. Hence, it is sterial colony.

After the complete growth of fungi from individual sample plated on agar plates, the culture plates were observed for the presence of various fungi grown. The individual colonies of fungi present in each culture plate plated with $1 \mathrm{ml}$ of soil sample were counted and the total number of colonies of fungi were calculated with reference to the dilution made. The population or total number of fungi present in soil sample is expressed as colony forming units ( $\mathrm{Cfu} / \mathrm{g}$ ) of soil sample. The total number of fungi and number of individual species of fungi present in $1 \mathrm{~g}$ of soil sample were recorded and calculated for the percentage occurrence.

\section{Maintenance of fungal cultures}

The frequently occurred individual species of fungi such as $A$. terreus, A. niger, $A$. flavus and Penicillium sp. occurred from soil samples were isolated and cultured in the agar slants containing PDA by subculture method. The 
sub cultured agar slants were incubated for the complete growth of fungi. Then the pure culture of fungi were labeled and stored in refrigerator for further reference in the laboratory and an in vitro growth experiments.

In vitro evaluation of $A$. terreus for Chromium (Chromium III sulphate) tolerance

Based on the frequency occurrence and the population of individual species of fungi from the soil samples of leather industry environment, the species Aspergillus terreus found to be a potential fungus. Therefore, the ability of growth of $A$. terreus isolated from the above soil samples was cultured in the Chromium amended (Chromium III sulphate $-\mathrm{Cr}_{2}\left(\mathrm{SO}_{4}\right)_{3}$ Potato dextrose broth (PDB) at the concentration level of 100ppm, $200 \mathrm{ppm}, 300 \mathrm{ppm}, 400 \mathrm{ppm}$ and $500 \mathrm{ppm}$. The inoculated culture medium flasks were kept in a shaker as well as at stable condition at room temperature for 5 to 7 days period. After 7 days period, the cultures were killed and the mycelium were filtered through whatman No.1 filter paper and dried at $70^{\circ} \mathrm{C}$ in hot air oven for 60 mins. Then the mycelial dry weight was recorded. Control PDB medium without Chromium amendment was inoculated with the above fungus and run the experiment parallel to the above.

In vitro evaluation of A.terreus for Herbicide (pretilachlor) tolerance

As mentioned above the frequently occurred species $A$. terreus was isolated from the soil samples of Paddy field environment and inoculated in the Herbicide (pretilachlor) amended PDB medium at the concentration level of 100ppm, 200ppm, 300ppm, 400ppm, 500ppm and $1000 \mathrm{ppm}$. The inoculated culture medium flasks were kept in shaker as well as at stable condition at room temperature for 5 days period. After 5 days, the cultures were killed and filtered through what man No.1 filter paper and dried at $70^{\circ} \mathrm{C}$ in hot air oven for $60 \mathrm{~min}$. Then the mycelial dry weight was recorded and the results were noted. Control medium without herbicide amendment was inoculated with the above fungus and run the experiment parallel to the above experiments.

\section{Statistical analysis}

Sufficient duplicates were made in each experiment and the mean values were calculated and $+/$ - SD values were expressed.

\section{RESULTS AND DISCUSSION Sample details}

Totally 12 soil samples including 6 from leather Industry environment of vellore district and 6 soil samples from paddy field environment of Thiruvallur District of Tamil Nadu were collected in the present study. The details of samples collected from different sources and their moisture content percentage were presented in the Table 1.

\section{Moisture content of soil samples}

The moisture content of soil samples from both the sources was determined and found

Table 1. Details of soil samples collection and it moisture content

\begin{tabular}{|c|c|c|c|c|}
\hline No. & Samples details & $\begin{array}{l}\text { Place of } \\
\text { collection }\end{array}$ & District & $\begin{array}{l}\text { Moisture } \\
\text { Content (\%) }\end{array}$ \\
\hline 1 & Sample - 1 (IS-1) & Ambur & Vellore & 12.4 \\
\hline 2 & Sample - 2 (IS-2) & Kilmurungai & Vellore & 16.6 \\
\hline 3 & Sample - 3 (IS-3) & Sethuvalai & Vellore & 12.2 \\
\hline 4 & Sample - 4 (IS-4) & Konavattam & Vellore & 8.0 \\
\hline 5 & Sample - 5 (IS-5) & Shenbakkam & Vellore & 8.6 \\
\hline 6 & Sample - 5 (IS-6) & Shenbakkam & Vellore & 16.0 \\
\hline 7 & Sample - 6 (PS-7) & Siruvapuri & Thiruvallur & 55.5 \\
\hline 8 & Sample - 7 (PS-8) & Ponneri & Thiruvallur & 21.6 \\
\hline 9 & Sample - 8 (PS-9) & Thervoy & Thiruvallur & 32.2 \\
\hline 10 & Sample - 9 (PS-10) & Periyapalaiyam & Thiruvallur & 6.8 \\
\hline 11 & Sample - 10 (PS-11) & Uthukottai & Thiruvallur & 25.2 \\
\hline 12 & Sample - 11 (PS-12) & Madharpakkam & Thiruvallur & 20.6 \\
\hline \multicolumn{5}{|c|}{ * - IS-1 to IS-6 - Industry environment soil samples } \\
\hline
\end{tabular}


in the range of $6.80 \%$ to $55.5 \%$ with an average of $19.64 \%$ for 12 soil samples. The highest moisture was observed in sample No.7 collected from paddy field soil as $55.4 \%$ and the lowest moisture as $6.8 \%$ in the sample No. 10 which also from paddy field soil. The frequency is as 4 samples less than $10 \%$, 3 samples 10 to $20 \%$, 3 samples 20 to $40 \%$ and 1 sample showed above $50 \%$ of moisture. The moisture content of different soil samples collected from the agricultural fields were found from $11.0 \%$ to $26.3 \%$ in which the groundnut and turmeric field show higher moisture as $26.0 \%$ and $26.3 \%$ and the lowest level was observed in sugarcane and tapioca soil with $11.0 \%$ and $17.0 \%$ respectively (Jayaraman et. al., 2018). However, in the present study, the higher moisture found in rice field soil is quite natural because of irrigation. The pattern of the moisture content of the individual soil samples were presented in Fig. 1. Analysis of fungi in soil samples

The individual soil samples collected from different environment of Leather industry and paddy field soil were analysed for the presence of qualitative and quantitative pattern of fungi. Out of 12 soil samples analysed, 8 samples were contaminated with higher population (15000 $\mathrm{cfu} / \mathrm{g}$ to $35,000 \mathrm{cfu} / \mathrm{g}$ ) with various individual species of fungi and remaining 4 samples occurred with moderate number $(4,000-15,000 \mathrm{cfu} / \mathrm{g})$ of population of fungi. For the quantitative

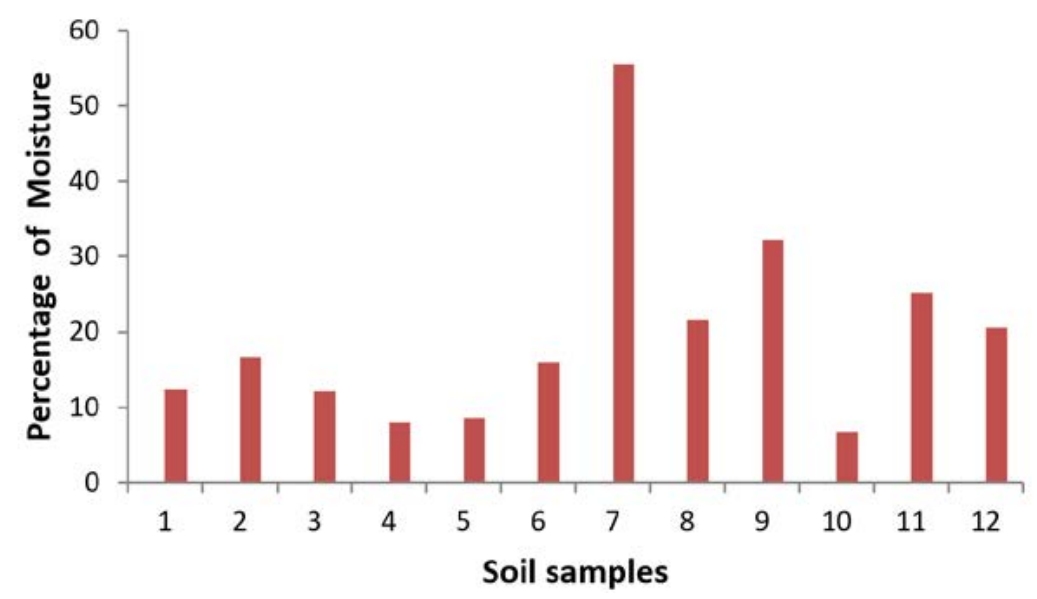

Fig. 1. The pattern of moisture contents of soil samples
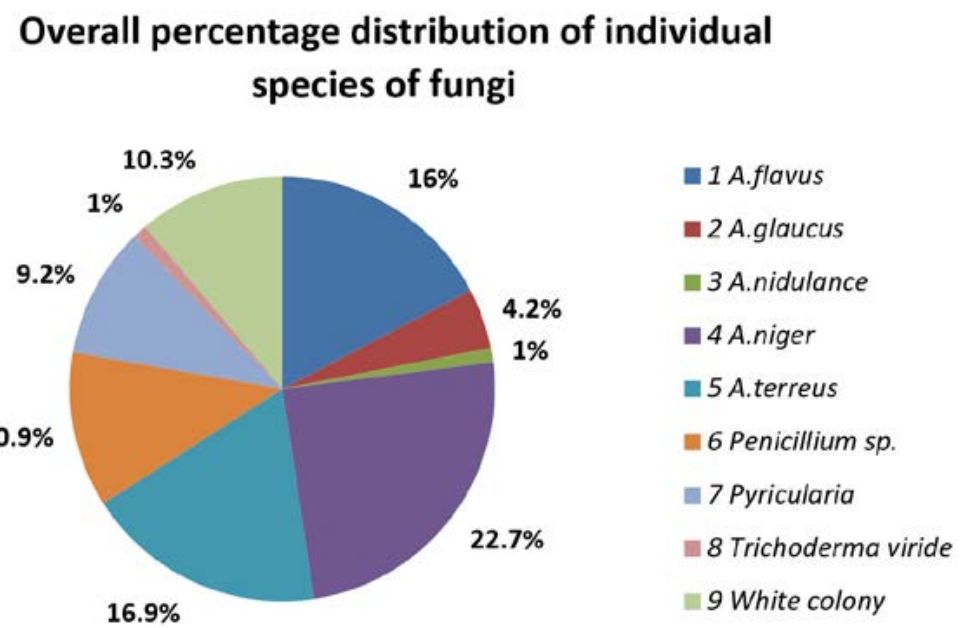

Fig. 2. Overall percentage occurrence of individual species of fungi in soil samples 


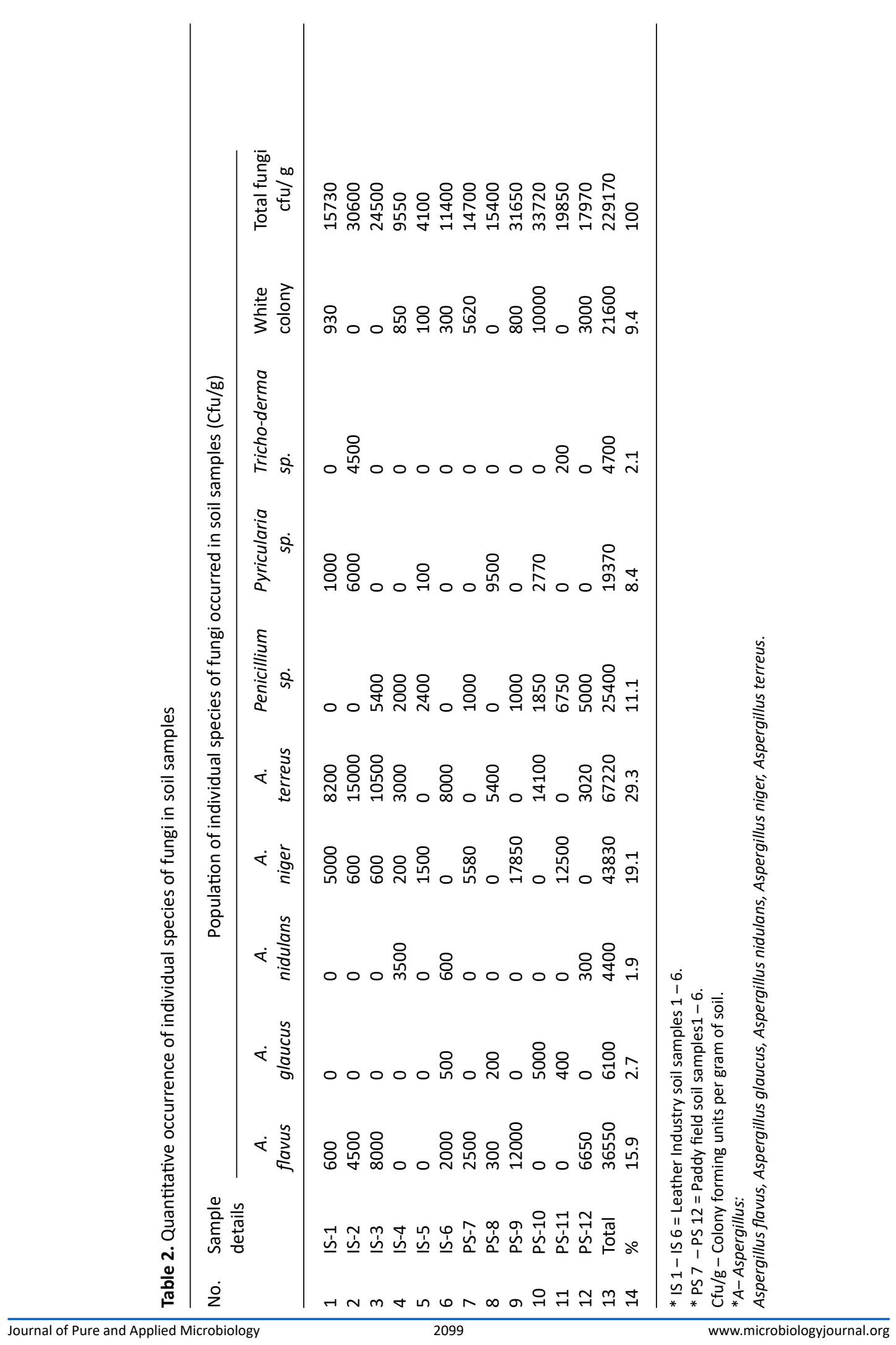


occurrence of individual species of fungi in the above 12 soil samples, it was observed as Aspergillus terreus, A.niger, A.flavus, penicillium $s p$. White non-sporulating fungus, Pyricularia sp., Trichoderma viride, A. glaucus and A. nidulans were occurred in the order of dominance. The previous report on the analysis of soil fungi from agricultural field shows enumeration of 22 species of fungi, in which Aspergillus niger, A. flavus, A. terreus, A. fumigatus, Trichoderma spp., Cladosporium cladosporioides, Curvularia lunata, Gliocladium $s p .$, Fusarium sp. and white non sporulating fungus (Jayaraman et. al., 2018; Selvaraj and Annamalai,
2011) which highlights the findings of present study. The highest frequency of occurrence and population of fungi is Aspergillus terreus 67,220 $\mathrm{Cfu} / \mathrm{g}$ in both the source of soil samples collected from Leather industries environment as well as paddy field soil. Whereas, the lowest number of occurrence of fungus is $A$. nidulans $4,400 \mathrm{Cfu} / \mathrm{g}$ . The average number of fungal colonies 19,098 $\mathrm{cfu} / \mathrm{g}$ in the soil sample. The population of fungi observed in the present study almost resembles the earlier report by Jayaraman et. al., (2018) which shows the highest number of fungi in plantain field as $28 \%$ followed by groundnut field

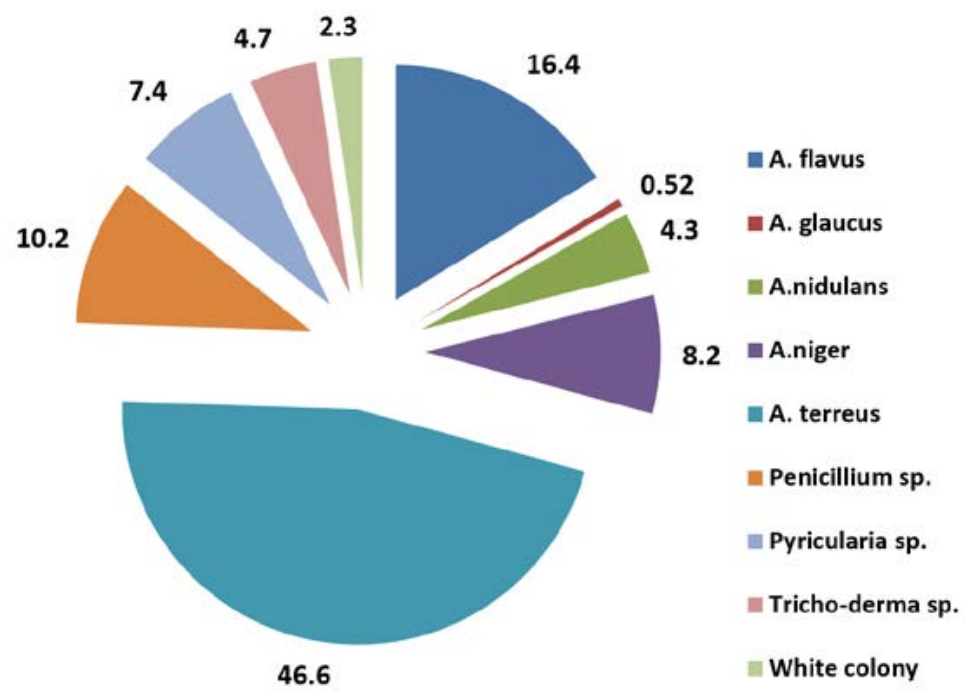

Fig. 3. Percentage distribution of fungi in soil samples of Leather industry Environment

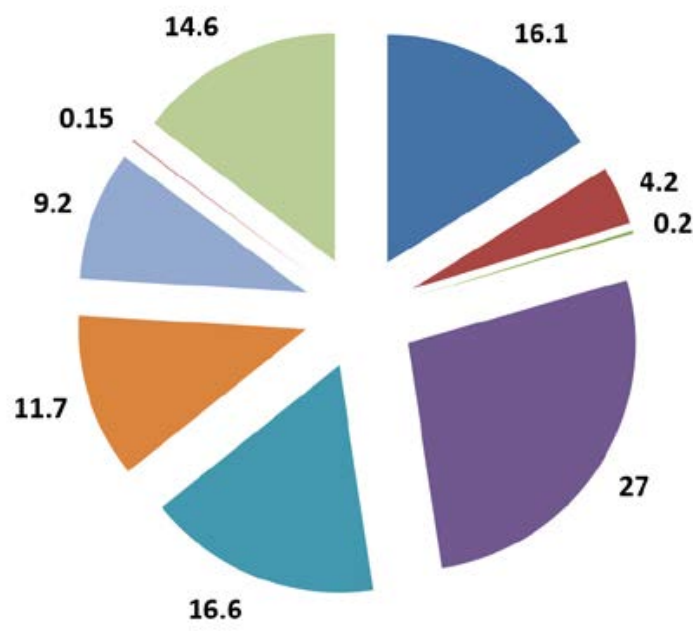

$$
\begin{aligned}
& =\text { A. flavus } \\
& =\text { A. glaucus } \\
& =\text { A.nidulans } \\
& =\text { A.niger } \\
& =\text { A. terreus } \\
& =\text { Penicillium sp. } \\
& =\text { Pyricularia sp. } \\
& =\text { Tricho-derma sp. } \\
& =\text { White colony }
\end{aligned}
$$

Fig. 4. Percentage distribution of fungi in soil samples of Paddy field environment 
(23\%), Sugarcane field (17\%), Tapioca and waste land soil each with $14 \%$ and the turmeric field soil has the lowest occurrence as $4 \%$ of fungal population. The details of occurrence of total number of fungi were presented in Table 2, and the percentage occurrence of individual species of fungi from the soil samples were presented in Fig. 2.

The overall percentage occurrence of individual species of fungi from the soil samples collected from different sites of leather industry environment and paddy field soil environment were calculated and compared. In Leather Indsutry environment, $A$. terreus was the dominant fungus

Table 3. Growth of $A$. terreus in chromium (Chromium III sulphate) amended medium in Shaking and stable culture condition

\begin{tabular}{cccc}
\hline No. & $\begin{array}{c}\text { Concen. } \\
\text { of } \mathrm{Cr} \\
\text { (ppm) }\end{array}$ & $\begin{array}{c}\text { Mycelial dry } \\
\text { weight } \\
\text { (mg/100ml) } \\
\text { (Shaking condition) }\end{array}$ & $\begin{array}{c}\text { Mycelial dry } \\
\text { weight } \\
\text { (mg/100ml) } \\
\text { (Stable condition) }\end{array}$ \\
\hline 1 & 100 & 220 & 310 \\
2 & 200 & 100 & 240 \\
3 & 300 & 60 & 140 \\
4 & 400 & 50 & 20 \\
5 & 500 & 0 & 0 \\
6 & Control & 610 & 420 \\
\hline
\end{tabular}

Concentrationof Chromium (ppm)

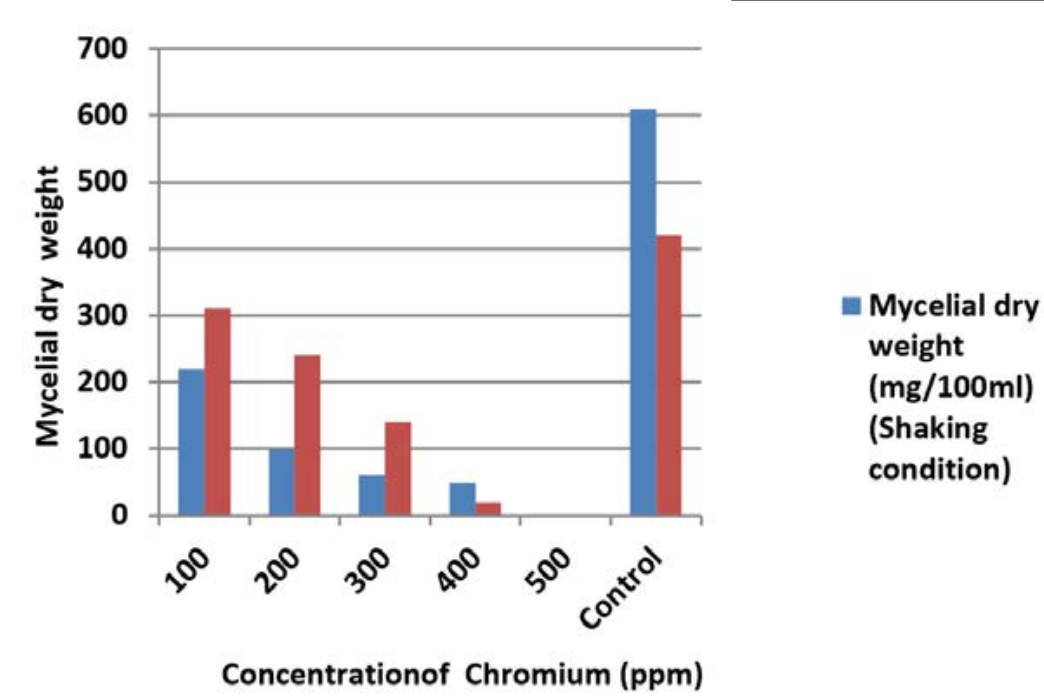

which occupies $46.6 \%$ followed by $A$. flavus (16.4\%) and Penicillium species (10.2\%), whereas other species of fungi were present less than $10 \%$. The paddy field soil shows the dominant species of fungi with A. niger (27\%) followed by A. terreus (16.6\%) and A. flavus (16.1\%). Other species of fungi were in lower level of occurrence $(<10 \%)$. The details were represented in the Fig. 3 and Fig. 4.

In vitro studies for Chromium (Chromium III sulphate) tolerance of Aspergillus terreus

The results of the in vitro study on the growth tolerance of $A$. terreus to Chromium showed that the growth was decreased from lower concentration (100ppm) to higher concentration

Table 4. Growth of $A$. terreus in Herbicide (pretilachlor) amended medium in Shaking and stable culture condition

\begin{tabular}{cccc}
\hline $\begin{array}{c}\text { No. Herbicide } \\
\text { concen. } \\
\text { (ppm) }\end{array}$ & $\begin{array}{c}\text { Mycelial dry } \\
\text { weight } \\
\text { (mg/100ml) } \\
\text { (Shaking condition) }\end{array}$ & $\begin{array}{c}\text { Mycelial dry } \\
\text { weight } \\
\text { (mg/100ml) }\end{array}$ \\
\hline (Stable condition)
\end{tabular}

Fig. 5. Growth of $A$. terreus in chromium (Chromium III sulphate) amended medium in Shaking and stable culture condition 


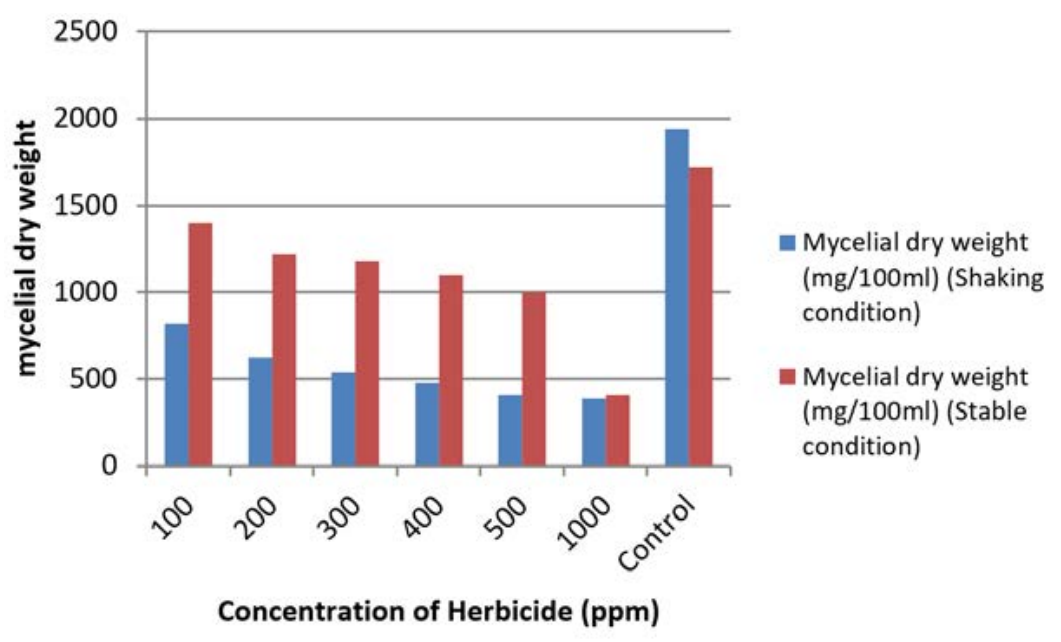

Fig. 6. Growth of $A$. terreus in Herbicide (pretilachlor) amended medium in Shaking and stable culture condition

(500ppm). Whereas, there was no growth of fungi observed at 500ppm concentration of PDB medium. The results were same in both shaking culture condition as well as at stable incubation condition except the amount of biomass of fungi. The mycelial dry weight of the fungi observed in the range from $310 \mathrm{mg} / 100 \mathrm{ml}$ at $100 \mathrm{ppm}$ to $20 \mathrm{mg} / 100 \mathrm{ml}$ at $400 \mathrm{ppm}$. But no growth was observed at $500 \mathrm{ppm}$ in both the incubation condition. This indicates that the presence of chromium in the nutrient medium disturb the growth metabolism of fungi and control the growth. The results were detailed in the table 3 and fig. 5. The requirement of Chromium as an essential micronutrient for the growth of many microorganisms for the maintenance of normal glucose, cholesterol and fatty acid metabolism up to certain level was reported in previous studies (Thacker et al., 2005). The results of the present study is in accordance with the findings of (Loreta Levinskaite, 2015) where certain soil fungi able to accumulate the $\mathrm{Cr}(\mathrm{IV})$ in their biomass especially on their cell wall up to certain concentration.

\section{In vitro studies for Herbicide (pretilachlor)} tolerance of Aspergillus terreus

For the in vitro tolerance study of A.terreus in herbicide (pretilachlor) amended potato Dextrose Broth (PDB) Medium, the results showed the gradual decrease of growth from $100 \mathrm{ppm}$ to $500 \mathrm{ppm}$ and $50 \%$ reduction in growth at $1000 \mathrm{ppm}$ of shaking and stable condition of culture when compared with control. The reduction of growth of fungi is quite rapid in shaking incubation condition than the inoculum kept in stable incubation condition. Degradation of herbicide (butachlor) by two isolates of fungi namely Aspergillus fumigatus and A. niger (87, 79\%) was studied by Sangeetha et al., (2018) and found to be highly degrading and form high level of biomass respectively. Paraquat, Glyphosate and Atrazine showed higher inhibition potency on certain fungal mycelial growth than Primextra and Linuron also were reported (Chukwuma., 2015). The details of growth of fungi in herbicide amended PDB were shown in table 4 and Fig. 6.

\section{CONCLUSION}

From the present study it is concluded that the soil samples of leather industry environment as well as paddy field environment contain versatile group of fungi which mainly comprised of Aspergillus and Penicillium species. Among the species of fungi encountered in both the soil environment, Aspergillus terreus was the dominant species in Leather industry environment followed by Aspergillus flavus, Penicillium sp. and Aspergillus niger. In the case of paddy field soil, even though A.niger was the dominant species followed by $A$. flavus, $A$. terreus also occurred with significant level of population. However, it is also concluded that from the observations of in vitro experimental study as the species $A$. terreus found to be a effective growth organism for tolerance of chromium (Chromium III sulphate) amended 
nutrient medium upto 500 ppm concentration. Further, for the herbicide supplemented growth medium, $A$. terreus able to tolerate and grown upto $1000 \mathrm{ppm}$ of herbicide concentration. Therefore, it is concluded from the present study, as the species of A.terreus can be used as a biological degrading agent for the polluted soil with chromium and herbicide contamination soil environment after conducting sufficient field trials.

\section{ACKNOWLEDGMENTS}

The authors are thankful to the Principal and HOD of the Institution for the facilities provided and support. Special thanks to farmers and Industries for providing us with data on history of site of sample collection.

\section{CONFLICT OF INTEREST}

The authors declare that there is no conflict of interest.

\section{AUTHORS' CONTRIBUTION}

All authors listed have made a substantial, direct and intellectual contribution to the work, and approved it for publication.

\section{FUNDING}

None.

\section{ETHICS STATEMENT}

Not applicable.

\section{DATA AVAILABILITY}

All datasets generated or analyzed during this study are included in the manuscript.

\section{REFERENCES}

1. Frac M, Jezierska-Tys S, Takashi Y. Occurrence, detection, and molecular and metabolic characterization of heatresistant fungi in soils and plants and their risk to human health. Adv Agron. 2015;132:161-204. doi: 10.1016/bs.agron.2015.02.003

2. Frac M, Weber J, Gryta A, et al. Microbial functional diversity in podzol ectohumus horizons affected by alkaline fly ash in the vicinity of electric power plant. Geomicrobiol J. 2017;34 579-586. doi: 10.1080/01490451.2016.1220651

3. Hannula SE, Morrien E, de Hollander M. Shifts in rhizosphere fungal community during secondary succession following abandonment from agriculture. ISME J. 2017;11:2294-2304. doi: 10.1038/ ismej.2017.90

4. Hannula SE, Morrien E, de Hollander M. Shifts in rhizosphere fungal community during secondary succession following abandonment from agriculture. ISME J. 2017;11:2294-2304. doi: 10.1038/ ismej.2017.90

5. Frac M, Hannula SE, Belka M, Jedryczka M. Fungal Biodiversity and Their Role in Soil Health. Front Microbiol. 2018;9:707. doi: 10.3389/fmicb.2018.00707

6. Rosas-Medina M, Jose G M-V, Piepenbring M. Diversity of Fungi in Soils with Different Degrees of Degradation in Germany and Panama. J Mycobiol. 2020;48(1):2028. doi: 10.1080/12298093.2019.1700658

7. Chandrashekar MA, Soumya Pai K, Raju NS. Fungal Diversity of Rhizosphere Soils in Different Agricultural fields of Nanjangud Taluk of Mysore District, Karnataka, India. Int J Curr Microbiol App Sci. 2014;3(5):559-566.

8. Akpomie OO, Bernard OE. Bioremediation Of Soil Contaminated With Tannery Effluent By Combined Treatment With Cow Dung And Microorganisms Isolated From Tannery Effluent. J Bioremediat Biodegrad. 2016;3:23-35. doi: 10.4172/21556199.1000354

9. Noorjahan CM. Physicochemical Characteristics, Identification of Fungi and Biodegradation of Industrial Effluent. J Environment and Earth Science. 2014;4(4).

10. Rasool A, Irum S. Toxic Metal E xic Metal Effect on Filament ect on Filamentous Fungi Isolated fr ungi Isolated from the Contaminated Soil of Multan and Gujranwala. J Bioresource Manage. 2014;1(2):38-51. doi: 10.35691/JBM.4102.0006

11. Jayaraman P, Kumar TN, Maheswaran P, Sahadevan E. In vitro studies on biodegrdation of Chlorpyrifos by Trichoderma virede and T. harzianum. J Pure Appl Microbiol. 2012;6(3):1465-1474.

12. Eze CS. In Vitro Screening Of Selected Herbicides On Rhizosphere Mycoflora From Yellow Pepper (Capsicumannum L Var. Nsukka Yellow) Seedlings In Nsukka, Enugu State, Nigeria Global. J Pure Appl Sci. 2015;21:113-123. doi: 10.4314/gjpas.v21i2.3

13. Martins PF, Martinez CO, de Carvalho G, et al. Selection of Microorganisms Degrading S-Metolachlor Herbicide. Brazilian Archives of Biology and Technology. 2007;50(1):53-159. doi: 10.1590/S151689132007000100019

14. Sangeetha M, Kanimozhi K, Panneerselvam A, Senthilkumar R. Biodegradation Of Herbicide Using Fungi Isolated From Paddy Fields Of Thanjavur District. J Pharm Drug Anal. 2018;6(2):297-301.

15. Arfarita N, Imai T, Prasetya B. Potential use of soilborn fungi isolated from treated soil in Indonesia to degrade glyphosate herbicide. J. Degraded And mining Landsmanagement. 2014;1(2):63-68 .

16. Seeger $M$, Hernandez $M$, Mendez $V$, Ponce $B$, Cordova M, Gonzalez M. Bacterial Degradation And Bioremediation of Chlorinated Herbicides And Biphenyls. J soil Sci Plant Nutr. 2010;10(3):320-332. doi: 10.4067/S0718-95162010000100007

17. Bhosle NP, Thore AS. Biodegradation of the Herbicide 2,4-D by Some Fungi, American-Eurasian. J Agric Environ Sci. 2016;16(10):1666-1671

18. Mishra PC, Patri M, Panda M. Growth of water hyacinth and its efficiency in the removal of pollution load from industrial waste. Journal of Ecotoxicology and 
Environmental Monitoring. 1991;1(13):218-224.

19. Waksman SA. A method of counting the number of fungi in the soil. J Bact. 1922;7:339-117. doi: 10.1128/ JB.7.3.339-341.1922

20. Warcup JH. The soil plate method for isolation of fungi from soil. Nature. 1950;166:117-118. doi: 10.1038/166117b0

21. Gilman JC. A Manual of Soil fungi, 2nd Indian edition, Biotech Books, Delhi. 2001.

22. Raper KB, Fennell DI. The genus Aspergillus, Baltimore: The Williams and Wilkins co. 1965:686.

23. Raper KB, Thom C. A manual Penicillia Baltimose: The Willams and Wilkins co.1949:875.

24. Barnett HL, Hunter BB. Illustrated Genera of Imperfect Fungi. The American Phytopathological society. APS press, St. Paul, Minnesota. 1948:218.
25. Ellis MB. More dematiaceous Hyphomyces, Commonwealth Mycological Institute. Pub., Kew, Survey, England. 1976.

26. Jayaraman P, Shalini S, Saraswathi K, Vadamalai K, Logambal R. Comparative Studies on Fungal Biodiversity of agricultural field soil from Thiruvannamalai District, Tamil Nadu, India. Int J Curr Microbiol App Sci. 2018;7(7):4259-4273. doi: 10.20546/ ijcmas.2018.707.497

27. Thacker U, Madamwar D. Reduction of Toxic Chromium and Partial Localization of Chromium Reductase Activity in Bacterial Isolate DM1. World J Microbiol Biotechnol.2005;21: 891-899. doi: 10.1007/s11274004-6557-7

28. Levinskaite L. Response of soil fungi to chromium(VI) Article in Ekologia, Institute of Botany, Zaliuju ezeru 49, LT 2021 vilnius, lathuania. 2015:10-13. 